Document downloaded from:

http://hdl.handle.net/10251/94475

This paper must be cited as:

Amigó, V.; Bonache Bezares, V.; Teruel Biosca, L.; Vicente-Escuder, A. (2006). Mechanical properties of duplex stainless steel laser joints. Welding International. 20(5):361-366. doi:10.1533/wint.2006.3582

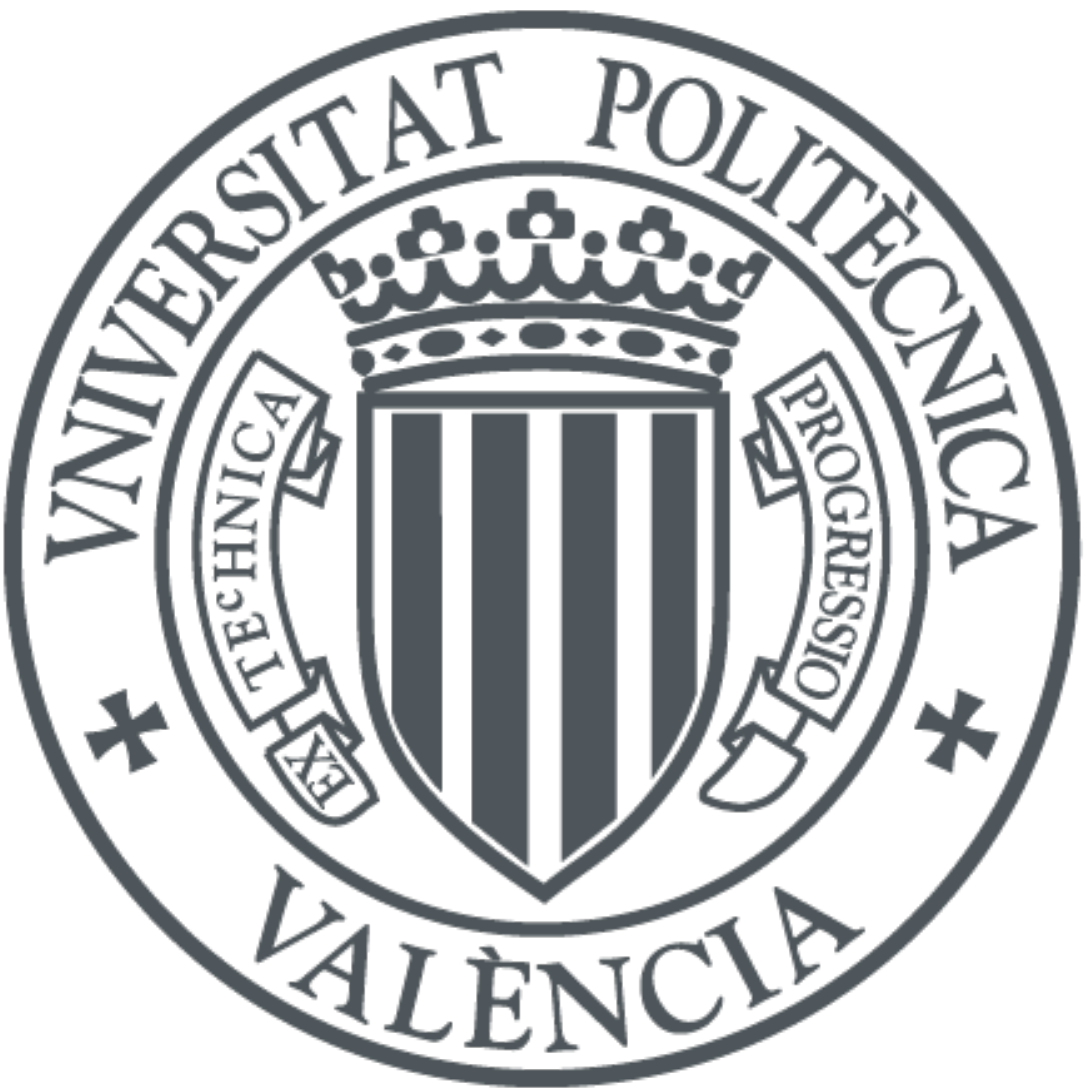

The final publication is available at

http://doi.org/10.1533/wint.2006.3582

Copyright Taylor \& Francis

Additional Information 


\title{
Mechanical properties of duplex stainless steel laser joints
}

\author{
V. AMIGÓ, V. BONACHE, L. TERUEL and A. VICENTE \\ Department of Mechanical Engineering and Materials, Universidad Politécnica de \\ Valencia, Spain
}

\section{Introduction}

The duplex stainless steels family is halfway between austenitic and ferritic stainless steels and combines the best aspects of both. Due to their combination of excellent mechanical properties and corrosion resistance, duplex stainless steels are used in a wide range of applications such as the chemical, petrochemical, food, paper, pharmaceutical and marine industries as well as in many other fields. ${ }^{1,2}$

Duplex stainless steels have now become the principal product competing with austenitic stainless steels as they combine a high elastic limit and toughness with excellent corrosion resistance in the temperature range between $-50{ }^{\circ} \mathrm{C}$ and $+250{ }^{\circ} \mathrm{C}$, which allows thinner material to be used, saving material and reducing costs. ${ }^{3,4}$

Duplex stainless steels contain a microstructure comprising 35-75\% ferrite with the remainder being austenite, ${ }^{5}$ although their properties are at their optimum when their austenite-ferrite ratios by volume are approximately $1: 1 .^{6,7}$ This equilibrium depends upon chemical composition and upon the thermo-mechanical processing conditions, ${ }^{8}$ so it is essential that this is monitored during manufacturing processes and while in service. $^{9}$

Despite their sophisticated microstructure, conventional welding processes can be used to weld duplex stainless steels and the most significant problem stems from the biphasic microstructure of which they are constituted, together with the precipitation of intermetallic phases that in practice renders welding somewhat more complex than with austenitic stainless steels. ${ }^{10}$

In general, duplex composites solidify like ferrite and the austenite is formed through nucleation during cooling in the solid state $\left(1300-800^{\circ} \mathrm{C}\right)$, meaning that the high cooling speeds associated with welding change the equilibrium of the phases producing a ferritization of the welded material. ${ }^{11}$ Another problem associated with the welding of duplex stainless steels is precipitation during the cooling of inter-metallic phases such as phase $\sigma$, phase $\chi, \mathrm{Cr}_{23} \mathrm{C}_{6}, \mathrm{Cr}_{2} \mathrm{~N}$, especially in the heat affected zone, ${ }^{12,13}$ which leads to a great reduction in toughness, while also affecting resistance to corrosion through pitting and cracking. ${ }^{14}$ These problems can be avoided through the addition of stabilizing elements of austenite, the usual practice being to use overalloyed filler materials with about 2-4\% more nickel than the base metal. The ferrite/austenite ratio also depends upon the heat input into the weld, given that this controls the cooling speed and thus the transformation of ferrite into austenite based upon diffusion. The heat input therefore has to be sufficiently high to promote such a transformation, thereby achieving a favourable equilibrium between the phases, but sufficiently low to avoid precipitation of the intermetallic phases due to the low cooling speed. ${ }^{15,16}$ Another consideration to bear in mind when welding this material is that neither preheating nor post-heating treatments are recommended as they promote unwanted precipitation of phases. ${ }^{5,17}$ 
Several published works present a preliminary data framework that highlights the good laser beam weldability of duplex stainless steels. ${ }^{18,19}$ Laser welding is a highdensity process in terms of energy, but with a low heat input, between five and eight times less than with conventional welding methods such as submerged arc welding.20,21 This induces very rapid thermal cycles in the material with heating speeds of around 104 ${ }^{\circ} \mathrm{C} / \mathrm{s} 22$ and consequently rapid cooling speeds that produce weld beads with a high penetration/width ratio, exceptionally small heat affected zones and a reduction in residual stresses and heat distortion. Other benefits that render this technique attractive are its high production capacity, repeatability and capacity for automation. ${ }^{23}$

This work presents the influence of welding parameters on the microstructural parameters and mechanical behaviour of welded joints. In doing so, we seek to establish the microstructural changes in the molten area and the heat affected zone, which will define the mechanical properties of the welded joints. This mechanical behavior is evaluated by means of traction tests on welded test pieces and microhardness scanning of the heat affected zone.

\section{Description of experiment}

The material used in this research was $2 \mathrm{~mm}$ thick laminated sheets of Thyssen NIROSTA 4462 duplex stainless steel (EN X 2CrNiMoN 225 3), the basic composition of which is $0.03 \% \mathrm{C}, 1.00 \% \mathrm{Si},<2.00 \% \mathrm{Mn}, 22.00 \% \mathrm{Cr}, 5.50 \% \mathrm{Ni}, 3.00 \% \mathrm{Mo}$ and $0.20 \% \mathrm{~N}$, and powder metallurgy duplex steel rods composed of 50\% 316L/50\% 434, the sintering process for which involves heating at $5{ }^{\circ} \mathrm{C} / \mathrm{min}$ up to a temperature of 1250 ${ }^{\circ} \mathrm{C}$, maintained for 30 minutes and cooling to about $700{ }^{\circ} \mathrm{C}$ at a speed of $5{ }^{\circ} \mathrm{C} / \mathrm{min}$. The basic microstructure of both materials is shown in Fig. 1.

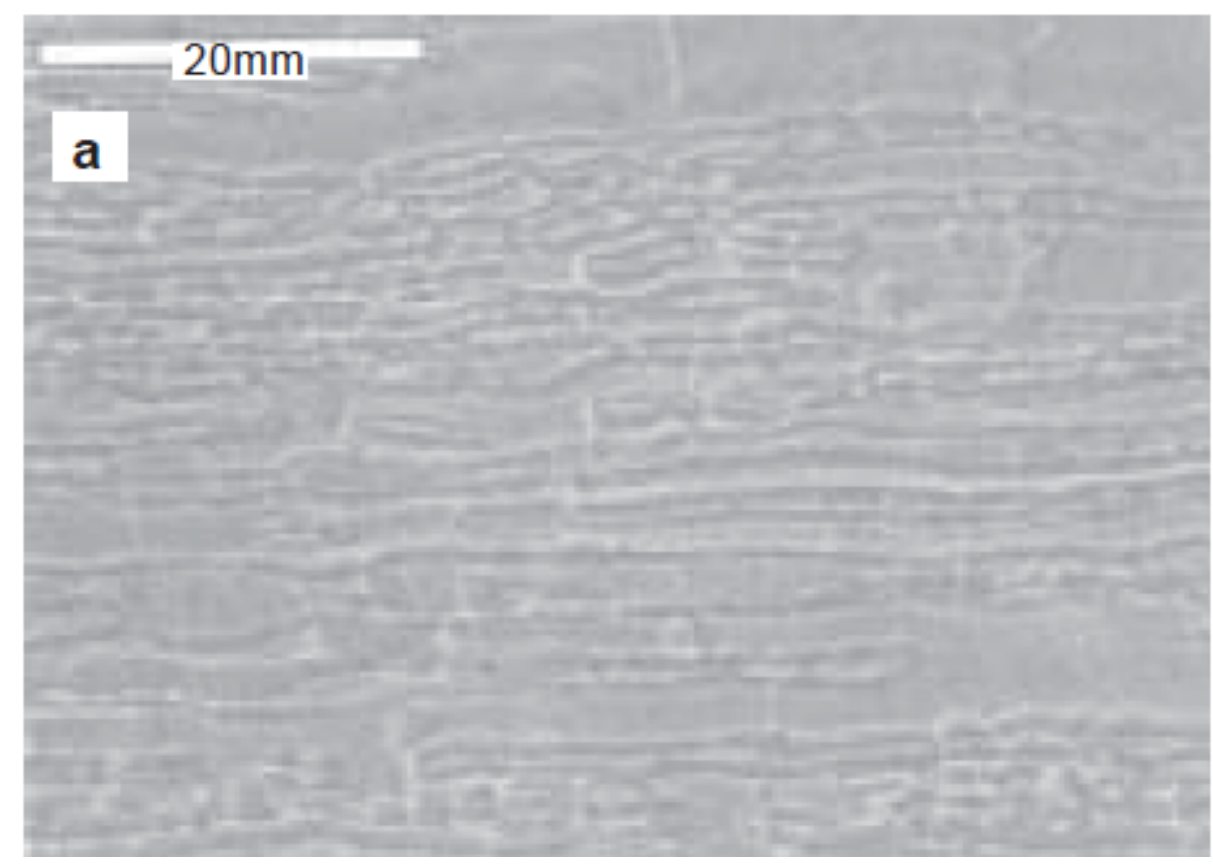




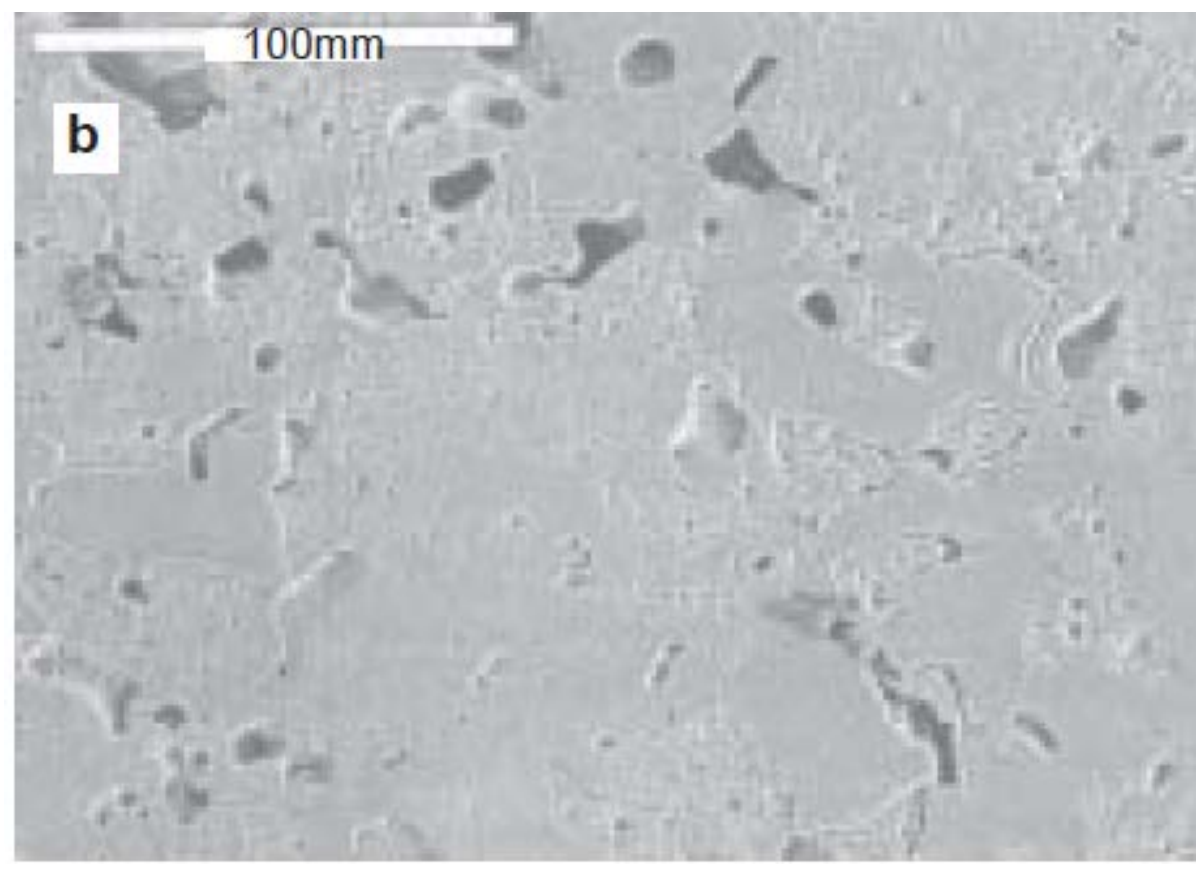

1 (a) Mill duplex stainless steel microstructure after etching with Murakami obtained with SEM; (b) Microstructure of sintered duplex stainless steel after etching with Murakami obtained with SEM.

The welded joints were made without filler material, irradiating the butt joints with an $\mathrm{Nd}-$ YAG laser with a maximum power of $1000 \mathrm{~W}$, emitting a wavelength of $1064 \mathrm{~nm}$ (near infra-red) that has continuous and pulsed emission modes. We used a coaxial argon filler head that had the dual function of protecting the optics of the head from emissions of particles and gases from the material that was being welded and of providing an oxygen-free protective atmosphere for the welding zone. The welds were performed in continuous mode at maximum laser power and with $15 \mathrm{~mm}$ defocussing. Having confirmed the ideal conditions in which to achieve a suitable penetration of the bead, with a minimum gap, the table feed speeds were 300 and $400 \mathrm{~mm} / \mathrm{min}$ for the forging material and 200 and $250 \mathrm{~mm} / \mathrm{min}$ for the powder metallurgy material.

For the forging steel, we cut sheets measuring $140 \times 60 \mathrm{~mm}$ at an oblique to the lamination, so that upon welding the bead was left at $90^{\circ}$ to the direction of the lamination. The traction test pieces were cut by laser.

The mechanical characterization of the welded joints was achieved through traction tests with Instron 4204 equipment with a maximum load of $50 \mathrm{kN}$ and microhardness tests with Matsuzawa MHT2 equipment working with a load of 200gf for 20 s, whereby we obtained different scans from right across the heat affected zone.

The macroscopic observations of the beads were achieved using a Nikon SMZ800 stereoscopic microscope. The testing was completed with a microstructural study, for which we used conventional metallographic techniques on cuts at an oblique angle to the weld. The samples were etched with Murakami (10g potassium permanganate, $10 \mathrm{~g}$ $\mathrm{KOH}$ and $100 \mathrm{ml} \mathrm{H2O}$ at $60{ }^{\circ} \mathrm{C}$ for 10 mins for the laminated material and approximately 40 mins for the powder metallurgy steel) and observed through an optical microscope (Nikon Microphot FX) and scanning electron microscopy (JEOL JSM 6300). 

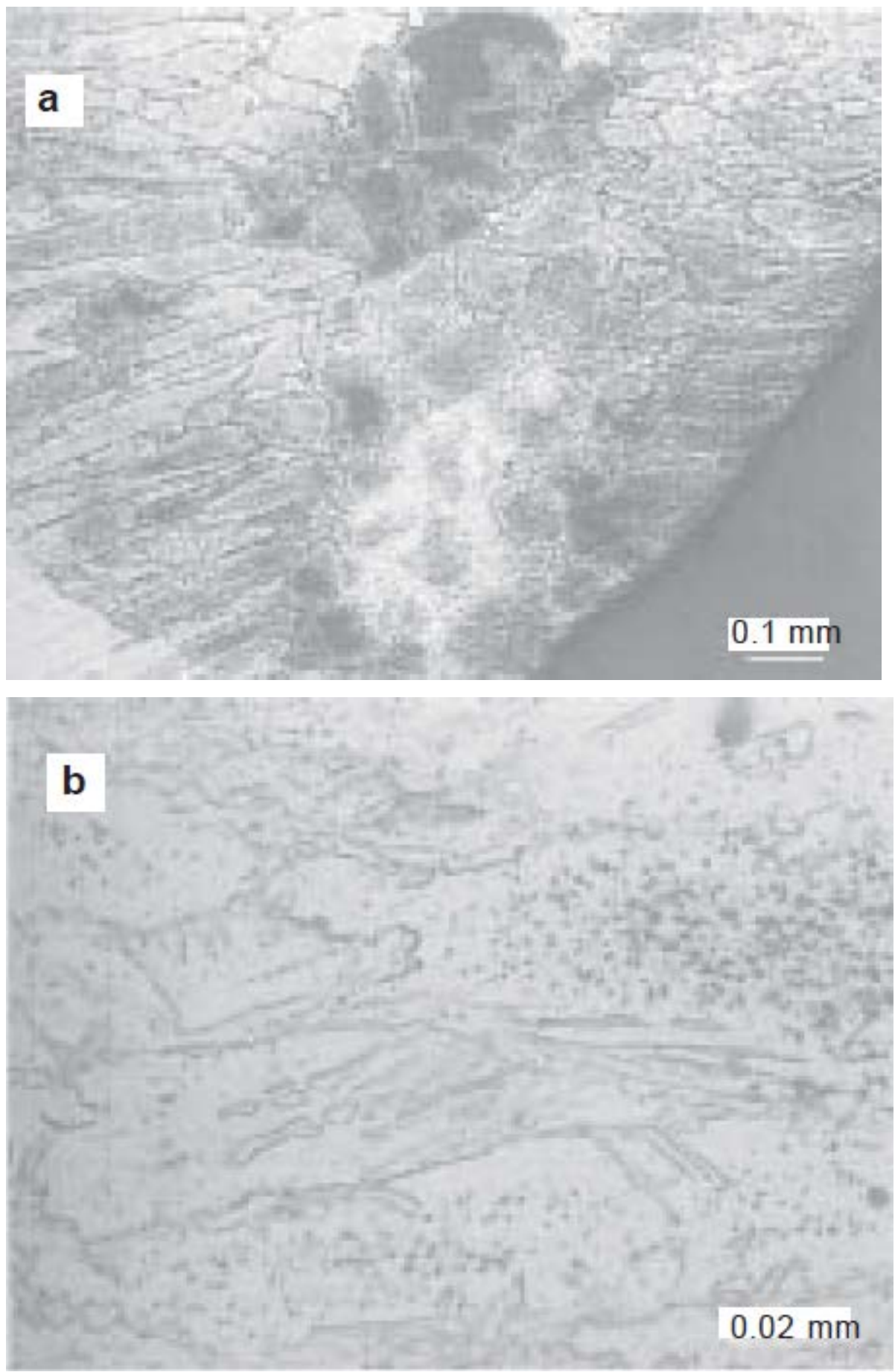


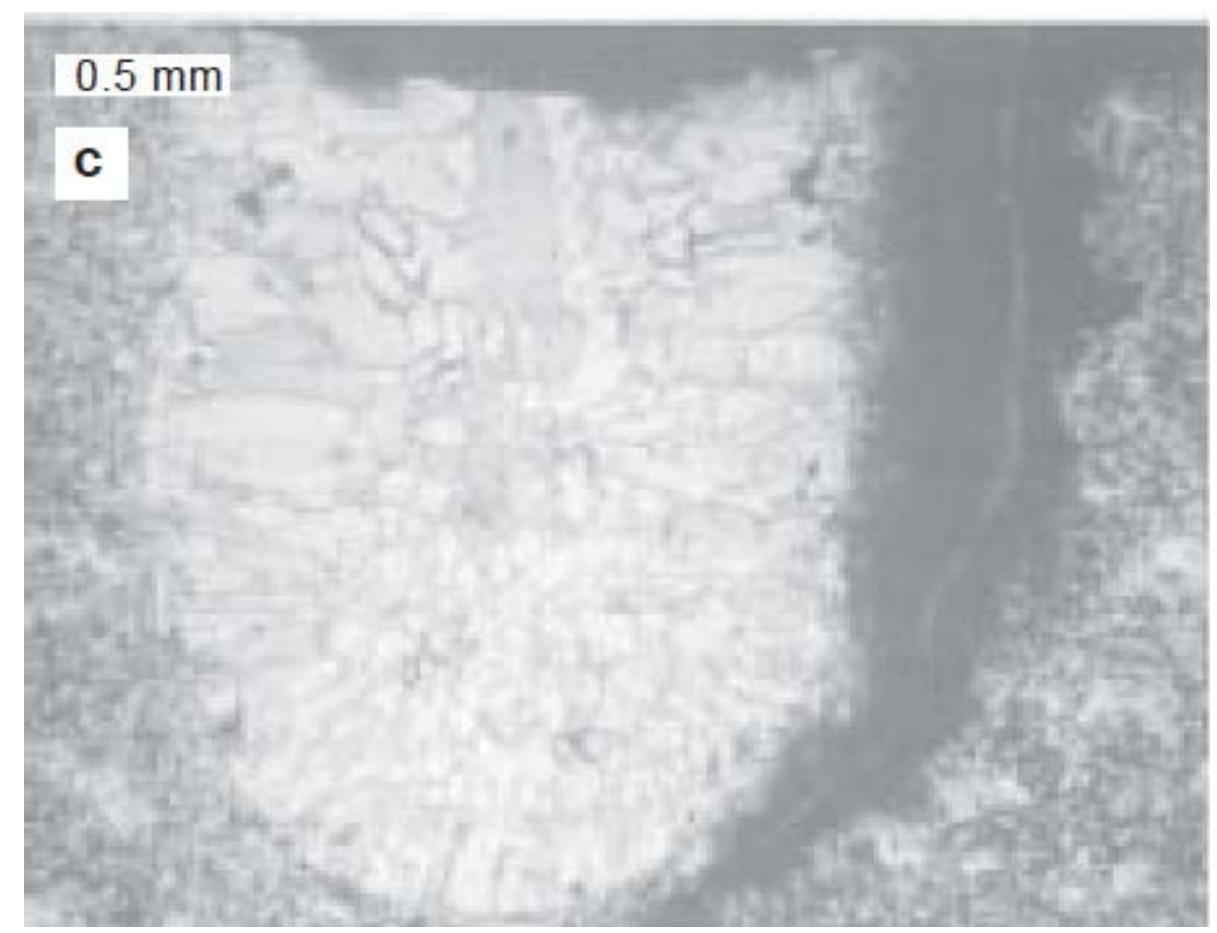

2 (a) Micrograph of mill duplex stainless steel welded at $300 \mathrm{~mm} / \mathrm{min}$. after etching with Murakami obtained with optical microscopy; (b) Detail HAZ of Fig. 2(a); (c)

Micrograph of sintered duplex stainless steel welded at $200 \mathrm{~mm} / \mathrm{min}$ after etching with Murakami obtained with optical microscopy.

\section{Findings and discussion}

\section{Microstructure}

In both materials, we observed an essentially ferritic solidification in the structure through an alteration in the equilibrium due to the high cooling speed, as demonstrated in Fig. 2. The ferritic phase reveals a structure of equiaxed grains in the centre of the fusion zone and thickened columnar grains, typical of competitive epitaxial growth. Especially on the edges of the ferrite grain, the austenite precipitates incipiently as allotriomorphic austenite that serves for the nucleation of Widmanstäten austenite and within the ferrite grains in an acicular shape. The HAZ is characterized by its very narrow width and one only sees a thickening of the ferrite grains once dissolution of the austenite is apparent. Given the techniques employed for microstructural analysis, we are unable to confirm the presence of intermetallic compounds, which constitute the principal problem in the welding of duplex stainless steels.

Behaviour in response to traction

The effect of laser welding on the behaviour of the forged material in response to traction can be seen in Fig. 3.

The results obtained are shown in Table 1 , where one can see that the microstructural changes in the molten area and the HAZ barely affect the good resistance qualities of the weld, while the plastic parameters suffer significant losses.

At welding speeds of 300 and $400 \mathrm{~mm} / \mathrm{min}$, respectively, one sees a loss in maximum resistance of $9.2 \%$ and $11.3 \%$, a fall of $16.7 \%$ and $24.8 \%$ in elastic limit and a reduction in elongation at fracture of $54 \%$ and $69.7 \%$. 
Table 1 Tensile test results of mill duplex stainless steels

\begin{tabular}{|l|l|l|l|l|}
\hline & $\begin{array}{l}\text { Elastic limit } \\
(\mathrm{MPa})\end{array}$ & $\begin{array}{l}\text { Maximum } \\
\text { resistance } \\
(\mathrm{MPa})\end{array}$ & $\begin{array}{l}\text { Elongation at } \\
\text { fracture (\%) }\end{array}$ & Constriction \\
\hline Base metal & 681 & 840 & 27.4 & 44.1 \\
\hline $\begin{array}{l}\text { Speed: } 300 \\
\mathrm{~mm} / \mathrm{min}\end{array}$ & 567 & 763 & 12.6 & 8.6 \\
\hline $\begin{array}{l}\text { Speed } 400 \\
\mathrm{~mm} / \mathrm{min}\end{array}$ & 512 & 745 & 8.3 & 10.2 \\
\hline
\end{tabular}

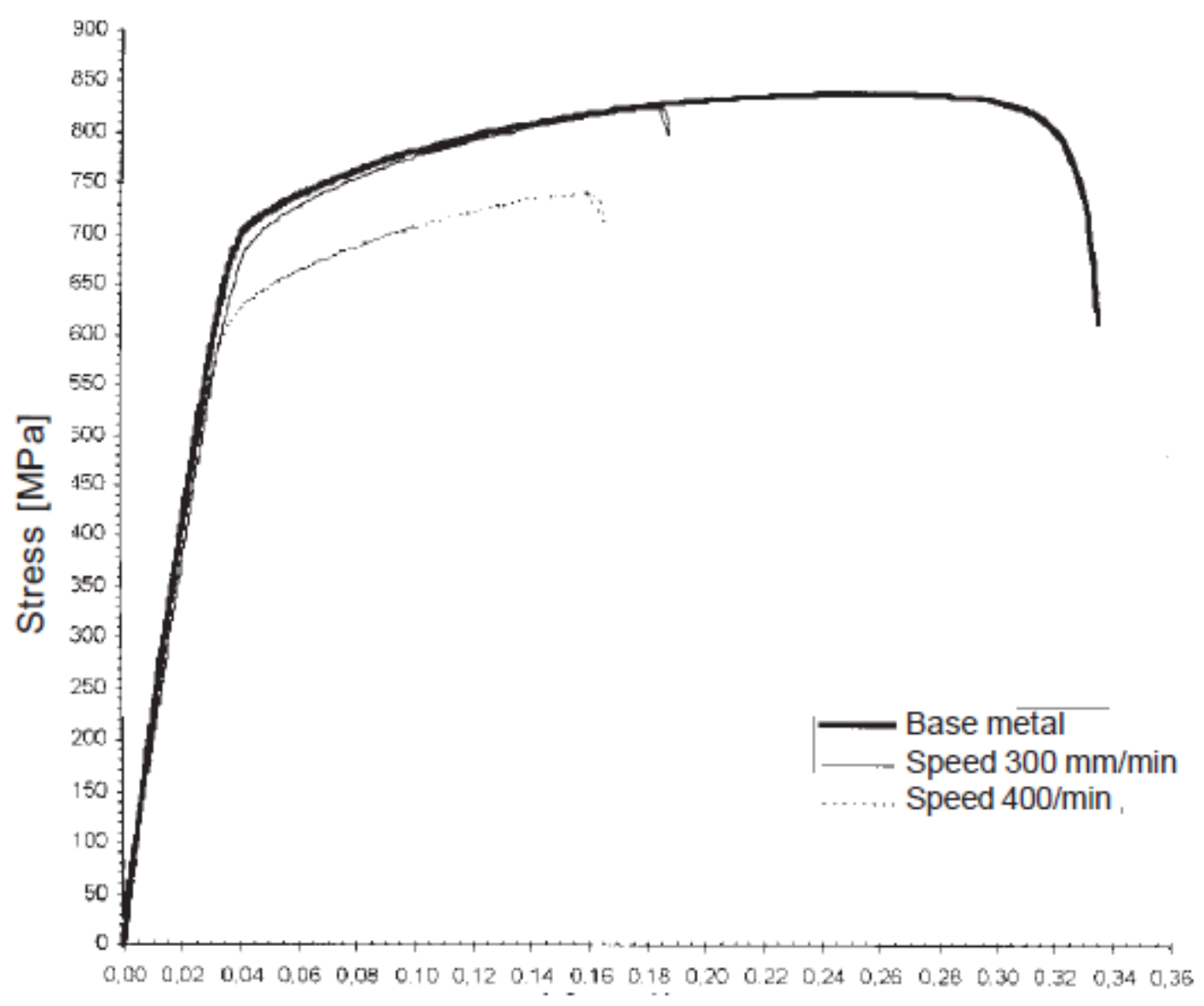

Deformation

3 Influence of welding speed on the tensile behaviour of mill duplex stainless steel.

The fracturing of the welded joints takes place through the fusion zone (Fig. 4a). The micrograph in Fig. 4b shows that despite the loss of plasticity caused by the welding, the fractures possess significant ductility, as evidenced by the appearance of deformation cavities typical of ductile fracture. 

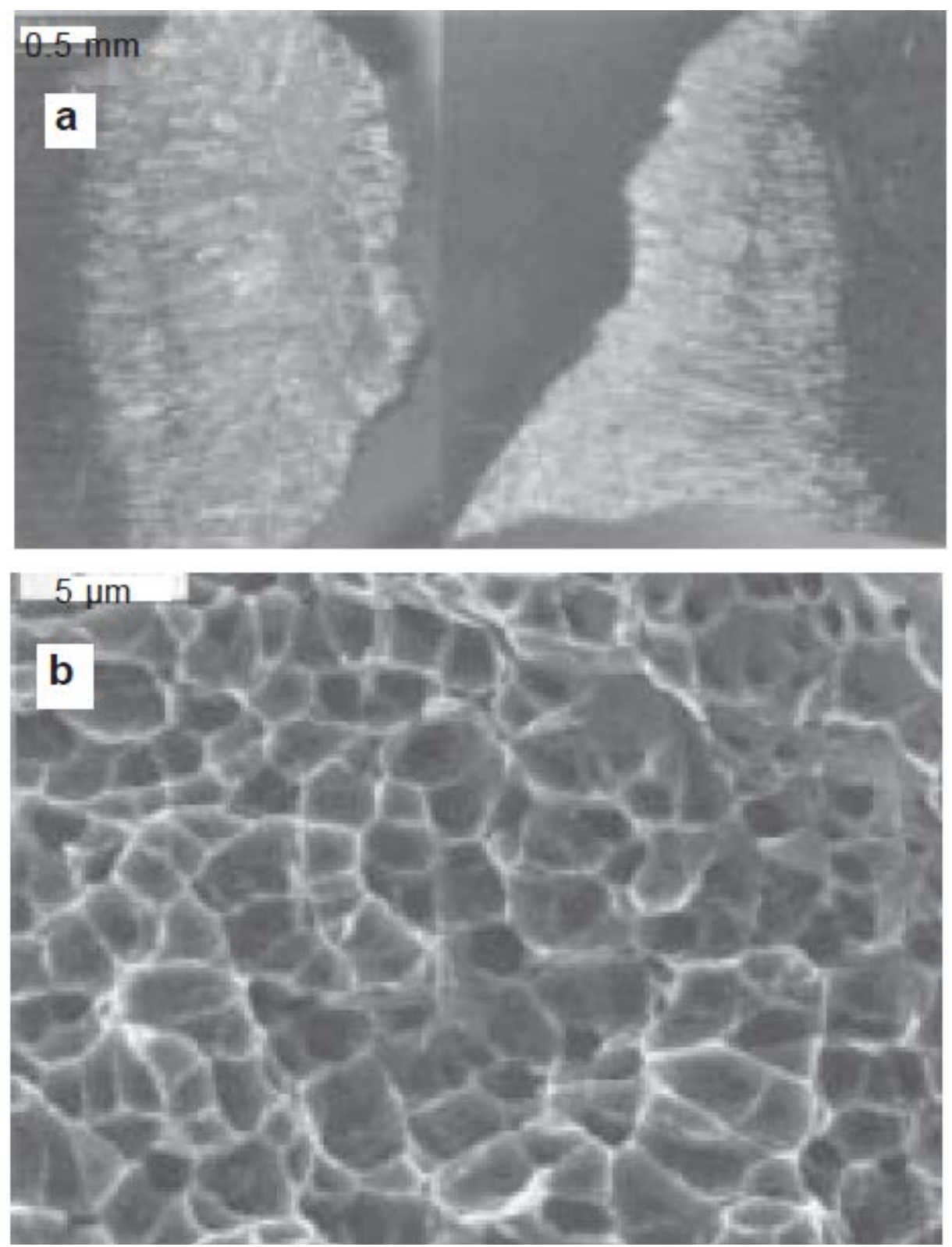

4 (a) Transverse view of the mill duplex stainless steel fracture welded at $300 \mathrm{~mm} / \mathrm{min}$ obtained with stereoscopic microscopy after etching with Murakami; (b) Micrograph of mill duplex stainless steel fracture welded at $300 \mathrm{~mm} / \mathrm{min}$ obtained with SEM.

The behaviour of sintered duplex stainless steel welded joints is shown in Fig. 5 and the values of the mechanical parameters obtained from the tension-deformation diagram are provided in Table 2. 


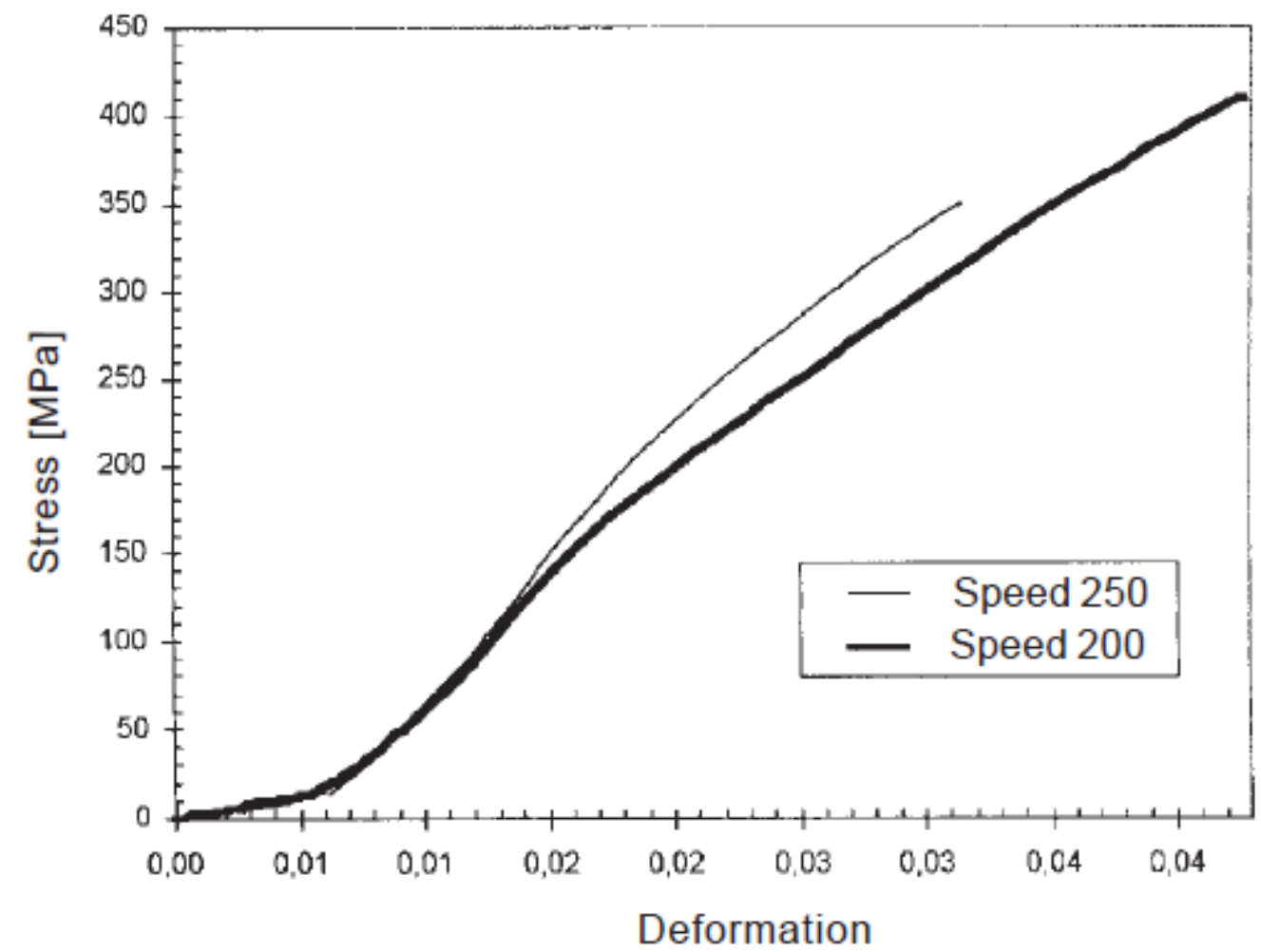

5 Influence of welding speed in the tensile behaviour of sintered duplex stainless steel.

Table 2 Tensile test results of sintered duplex stainless steels

\begin{tabular}{|l|l|l|l|l|}
\hline & $\begin{array}{l}\text { Elastic limit } \\
(\mathrm{MPa})\end{array}$ & $\begin{array}{l}\text { Maximum } \\
\text { resistance } \\
(\mathrm{MPa})\end{array}$ & $\begin{array}{l}\text { Elongation at } \\
\text { fracture (\%) }\end{array}$ & Constriction \\
\hline Base metal & 267 & 394 & 0.58 & 0.88 \\
\hline $\begin{array}{l}\text { Speed: } 300 \\
\text { mm/min }\end{array}$ & 255 & 386 & 0.5 & 0.7 \\
\hline $\begin{array}{l}\text { Speed } 400 \\
\mathrm{~mm} / \mathrm{min}\end{array}$ & 255 & 358 & 0.5 & 0.2 \\
\hline
\end{tabular}

As with the forging material, the resistance parameters only fall in respect of the base material and by even less than with the laminated steels. For joints welded at 200 $\mathrm{mm} / \mathrm{min}$ we obtained falls of $2 \%$ in maximum resistance and of $4.2 \%$ in elastic limit; as regards plastic properties, we should point out that these suffer a more marked fall of $13.4 \%$ for elongation at fracture and of $20.4 \%$ for constriction, but without matching the falls obtained for forging steel. In the case of a speed of $250 \mathrm{~mm} / \mathrm{min}$, we obtained the same falls in elastic limit and elongation, whereas maximum resistance fell by $9.1 \%$ and constriction by $77.3 \%$. It is important to highlight the low plasticity of the sintered material compared to the forging material, due principally to high porosity and lack of bonding between grains. The micrographs for the fracture of a powder metallurgy duplex steel, welded at $250 \mathrm{~mm} / \mathrm{min}$ are provided; in Fig. 6, we see the comparative lack of bonding of the material, which contains a large quantity of intercommunicating pores and very little actual fracture area, while a detail from one of the joint areas is shown, in which one can see deformation cavities that appear to be ductile but that are much smaller than those observed for the forging steel (Fig. 4b). One also notes the 
presence of carbide precipitates that cause the anchoring of the dislocations, contributing to the reduction in plasticity.
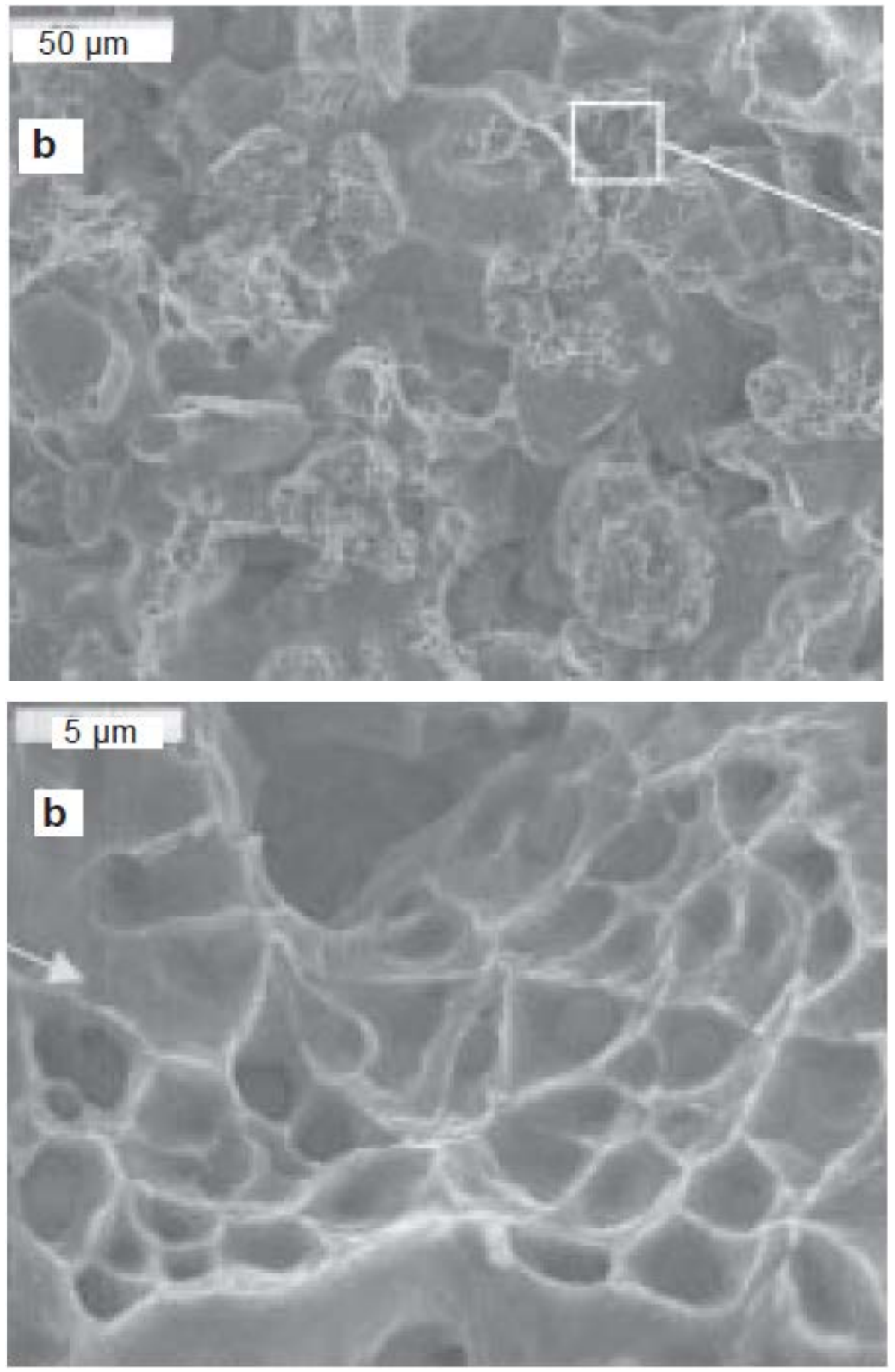

6 Micrographs of sintered duplex stainless steel fracture welded at $250 \mathrm{~mm} / \mathrm{min}$ obtained with SEM.

It must be stressed that, in this case, the fracture occurs in the base metal, in the zone adjacent to the HAZ despite the lack of penetration of the welds, as can be seen from Fig. 7. This is due to the reduction in porosity that the material undergoes in the welding area as a consequence of fusion. 
The effect of welding speed upon mechanical properties proved similar in the two materials examined; better results were obtained for welds performed at a lower speed, both with regard to parameters for resistance and for plasticity.
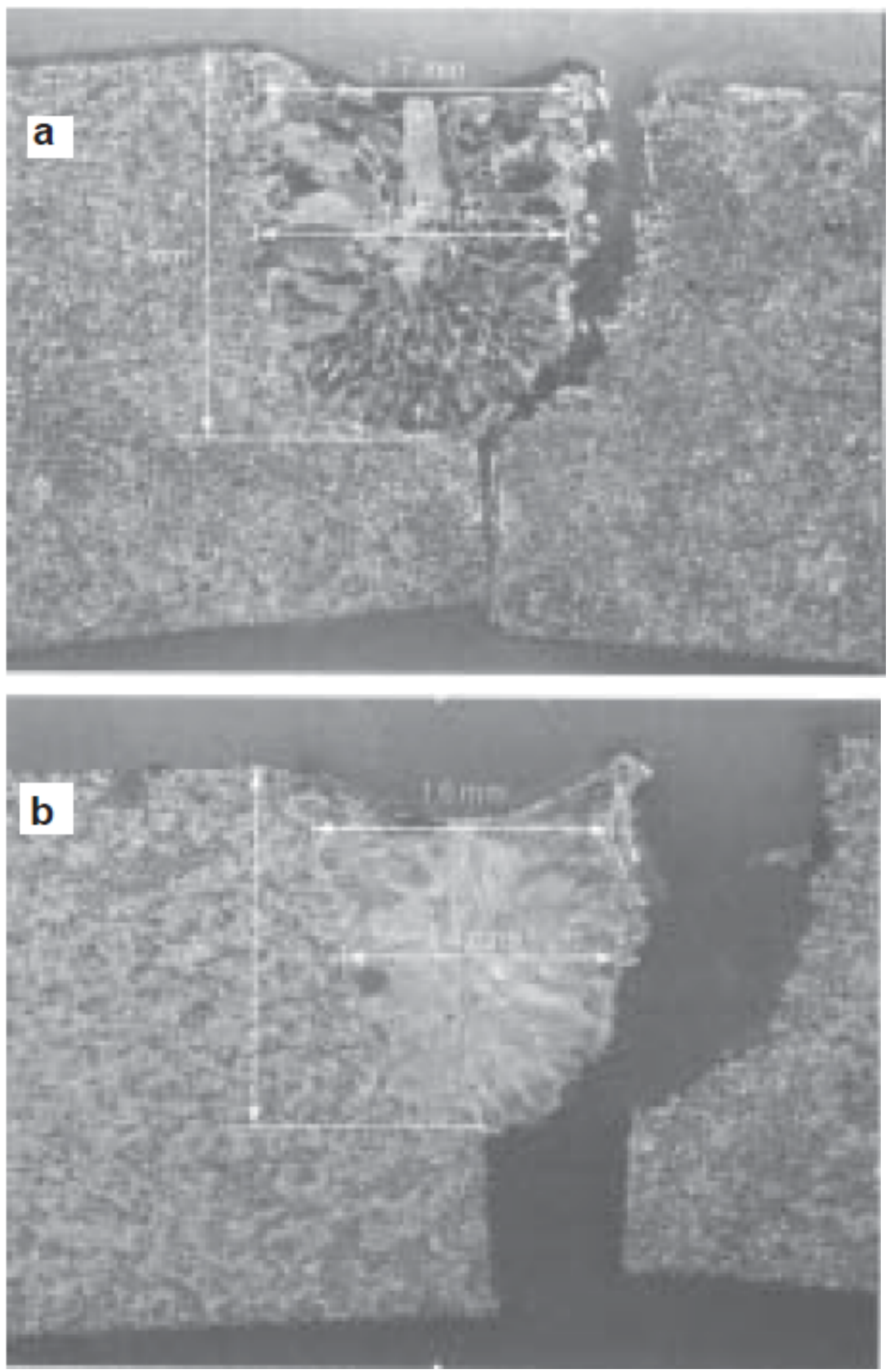

7 Transverse view of sintered duplex stainless steel fracture welded at different speeds, obtained with stereoscopic microscopy after etching with Murakami. (a) weld at 200 $\mathrm{mm} / \mathrm{min}$; (b) weld at $250 \mathrm{~mm} / \mathrm{min}$.

At a lower laser feed speed, the specific input energy increases, translating into a larger fusion zone and HAZ. In Fig. 7 one can see that, when the speed is reduced, the width of the heat affected zone increases, whereas there is no appreciable increase in the depth of penetration. 
The fact that the heat affected zone is narrower while achieving the same degree of penetration explains the better mechanical performance of the weld.

\section{Microhardness}

The microhardness findings for duplex stainless forging steels are shown in Fig. 8. The microhardness of the heat affected zone is $296 \mathrm{HV}$ when the welding speed is 300 $\mathrm{mm} / \mathrm{min}$ and it is $287 \mathrm{HV}$ at a speed of $400 \mathrm{~mm} / \mathrm{min}$. This compares with a microhardness rating of $278 \mathrm{HV}$ for the base metal, meaning that the increase in microhardness is $6.4 \%$ and $3.2 \%$, respectively. This increase is due to the ferritization that these zones experience, which offsets the effect of grain thickening. This might also be explained by the possible precipitation of inter-metallic compounds, especially chromium nitrides, due to the fact that the proportion of austenite in the heat affected zone is very low, meaning that the nitrogen saturates the ferritic phase and precipitates, rendering the material more fragile, while simultaneously reducing corrosion resistance.

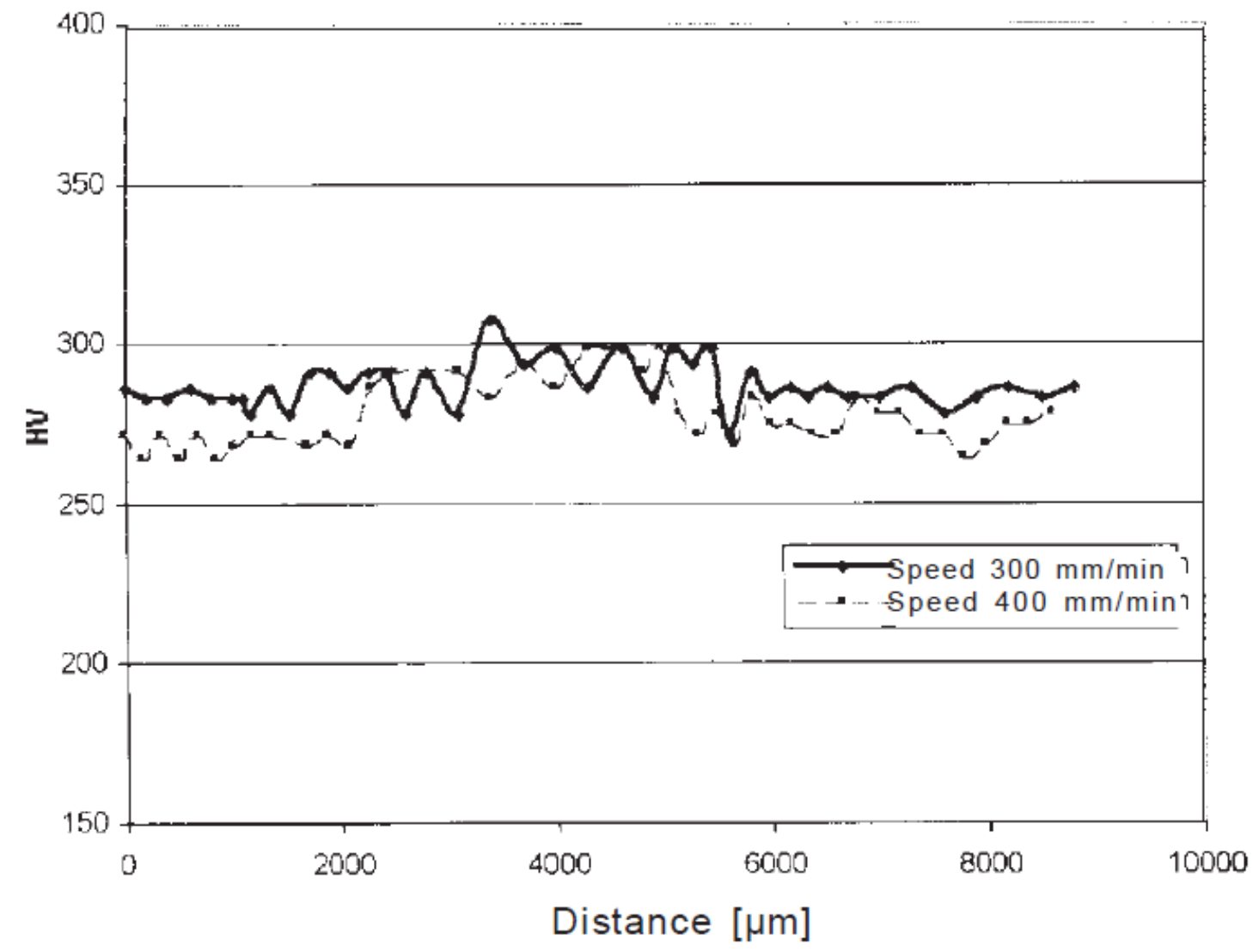

\section{Evolution of microhardness of mill duplex stainless steels.}

The powder metallurgy material displays great variability in its microhardness data as its structure is characteristic of sintered products. A more pronounced increase in microhardness is evident in the fusion zone and the HAZ as a consequence of the additional impact of the reduction in porosity. Fig. 9 shows the behavior of the sintered duplex stainless steel in this study, compared with powder metallurgy stainless steels composed of $100 \%$ 316L and 100\% 434, all of them welded at the same speed. The trend of all three is similar, but the figures obtained for the duplex are higher due to its inherent biphasic structure. For the base metal, we obtained an average figure of 166 $\mathrm{HV}$, well below the figure obtained for the forging duplex (278 HV) but well above the 
figures obtained for the 100\% 316L and 100\% 434 sintered steels (97 HV and $121 \mathrm{HV}$, respectively).

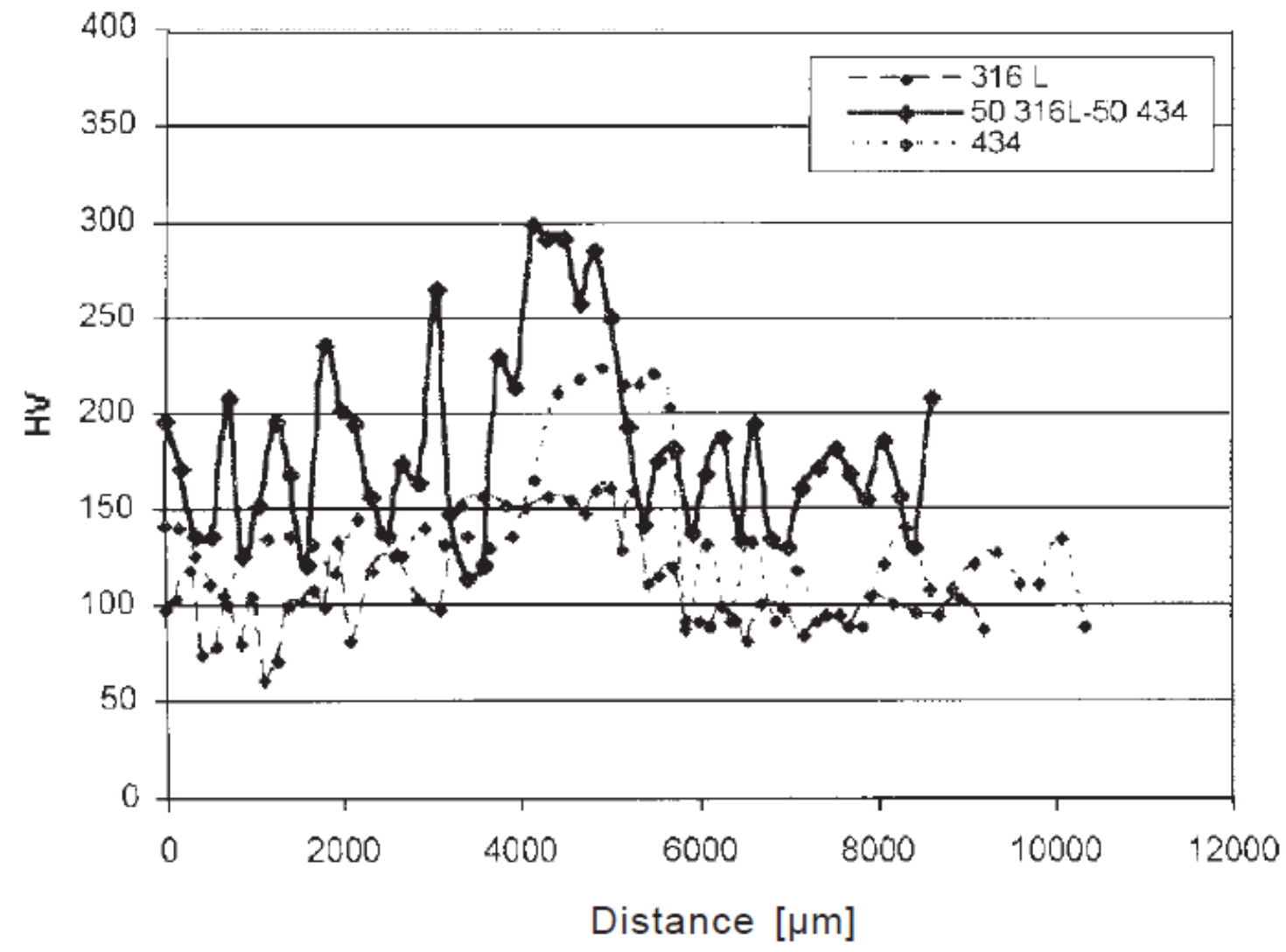

9 Evolution of microhardness of sintered duplex stainless steels.

The microhardness figure obtained in the weld zone is $264 \mathrm{HV}$, meaning that microhardness increases by $60 \%$ compared with the base metal, so that the weld produces similar microhardness figures in the heat affected zone for both duplex steels studied. This large increase is due to the almost complete reduction in porosity that is achieved by the material melting during welding.

\section{Conclusions}

Among the essential conclusions drawn from this research, we can highlight the following:

1 When laser welded, both forged and sintered duplex stainless steels demonstrate excellent properties of resistance, as their resistance is similar to that of the base metal and their elastic limit is not significantly affected. In addition, the elastic modulus also retains rigidity data similar to those of the base stainless steels.

2 The plasticity, elongation and constriction parameters reveal very major falls compared to the base steel, as a consequence of the increase in the ferrite/austenite ratio produced by the high cooling speed that is characteristic of the laser process. In the case of sintered steels, these falls are less dramatic but the limited plasticity of the base material is more accentuated.

3 For the materials studied, we obtained a better performance under traction by reducing welding speed, as even when a greater heat input is produced, one achieves the effect of 
reducing the cooling speed, affecting the microstructure obtained and, above all, the percentage of ferrite and austenite in the HAZ.

4 The increase in microhardness in the fusion zone and the HAZ is much greater for sintered steels than for forging steels and so one obtains similar data from the heat affected zone of the two materials despite the differences that exist in the base metals. This is explained by the reduction in the porosity of the sintered material due to the material becoming molten during welding.

\section{Acknowledgements}

The authors would like to express their gratitude to the Asociación de Investigación de Óptica de la Comunidad Valenciana [Community of Valencia Optics Research Association] for the application of the laser welds and to the Spanish Ministry of Science and Technology for its support through Project MAT2001-1123-C03-02.

\section{References}

1 Kacar R: Mater Des 200425 1-9.

2 Jiang Z H L et al: Mater Sci Eng 2003 A363 263-267.

3 Capello E et al: Mater Sci Eng 2003 A351 334-343.

4 Nilsson J O: Proc. Int. Conf. Duplex Stainless Steels 97 Maastricht, the Netherlands, KCI Publisher, p. 73, 1997.

5 Niset M and Daemen R: Mater Des 19855 291-293.

6 Liou H Y et al: Mater Chem Phys 200274 33-42.

7 Baeslack W A and Lippold J C: Met Constr 198820 26R.

8 Lippold J C et al: Varol, Fourth Int. Conf. Duplex Stainless Steels, Vol. 1, pp. 13-16, 1994.

9 Ramírez A J et al: Metall Mater Trans 2003 34A 1575-1597.

10 Karlsson L et al: Welding J 19951 (4-3) 28.

11 Chen T H and Yang J R: Mater Sci Eng 2002 A338 166-181.

12 Liou H-Y et al: Corros Sci 200244 2841-2856.

13 Sánchez I A et al: Rev. Metal. Madrid 200440 204-208.

14 Karlsson L et al: Proc. Int. Conf. Duplex America 2000 Houston, USA, KCI Publisher, p. 257, 2000.

15 Muthupandi, V et al: Mater Sci Eng 2003 A358 9-16.

16 McPherson NN A et al: J Mater Proc Technol 2003134 174-179.

17 Amado J M et al: Rev. Metal. Madrid 200440 365-368.

18 McPherson N A et al: Proc. Int. Conf. Stainless Steel 99, Chia Laguna, Italy, AIM Publisher, p.361, 1999.

19 Baxter C and McPherson N A: Proc. Int. Conf. Duplex America 2000, Houston, USA, KCI Publisher, p.315, 2000.

20 Kalla G et al: Fraunhofer-Institut für Lasertechnik, Aachen, Thyssen Stahl AG, Duisburg. 
21 Beyer E and Herziger G: Schweisstechnik Koll. Schweisstechnik, Aachen, 1989. 22 Haidemenopoulos G N: J. Alloys Compounds 2001320 302-307.

23 Zambon A and Bonollo F: Mater Sci Eng 1994 A178 203-207. 